\title{
PERCEPÇÕES DE ESTUDANTES DE ENFERMAGEM SOBRE A UTILIZAÇÃO DO PORTFÓLIO \\ REFLEXIVO
}

\author{
Antonio Germane Alves Pinto ${ }^{1}$ \\ Daniele Gomes da Silva ${ }^{1}$ \\ Estephani Vitorin॰ Correia da Silva ${ }^{1}$ \\ João Paulo Xavier Silva ${ }^{1}$ \\ José Adelmo da Silva Filho' \\ Pedro Paulo Rodrigues ${ }^{1}$ \\ Rachel Cardoso de Almeida ${ }^{1}$
}

\author{
http://orcid.org/0000-0002-4897-1178 \\ http://orcid.org/0000-0002-7605-9530 \\ http://orcid.org/0000-0002-2218-6075 \\ http://orcid.org/0000-0003-3082-9373 \\ http://orcid.org/0000-0002-0261-2014 \\ http://orcid.org/0000-0001-7026-0092 \\ http://orcid.org/0000-0001-8523-5842
}

Objetivo: Analisar as percepções de estudantes de graduação em Enfermagem sobre a utilização do portfólio reflexivo como método de ensino, aprendizagem e avaliação. Método: Pesquisa qualitativa, realizada em uma turma de acadêmicos de Enfermagem, os quais desenvolveram portfólios para a disciplina Tópicos Especiais do Cuidado de Enfermagem. Utilizou-se questionário sobre a percepção dos acadêmicos na construção do portfólio com ênfase em aspectos positivos e negativos do processo. Os dados foram categorizados pela análise de conteúdo temática. Resultados: Os resultados evidenciaram que a utilização do portfólio constitui uma ferramenta para superação do modelo tradicional de ensino, visando a reflexão do estudante no processo ensino-aprendizagem. O sucesso do uso do portfólio como metodologia ativa e método de avaliação depende da participação e interesse dos estudantes e professores. Conclusão: A reflexão no processo ensino-aprendizagem se torna possivel com a utilização de metodologias ativas. Como implicações para a prática de Enfermagem, o portfólio se mostrou uma estratégia eficiente para a ampliação do conhecimento teórico, auxiliando no desenvolvimento das habilidades e competências da profissão.

Descritores: Educação em Enfermagem; Aprendizagem; Avaliação educacional.

\section{PERCEPTIONS OF NURSING STUDENTS ON THE USE OF THE REFLECTIVE PORTFOLIO}

Objective: To analyze the perceptions of undergraduate nursing students about the use of the reflective portfolio as a teaching, learning and assessment method. Method: Qualitative research, conducted in a class of nursing students, who developed portfolios for the discipline Special Topics of Nursing Care. We used a questionnaire about the students' perception in the portfolio construction with emphasis on positive and negative aspects of the process. Data were categorized by thematic content analysis. Results: The results showed that the use of the portfolio is a tool for overcoming the traditional teaching model, aiming at student reflection in the teaching-learning process. The success of using the portfolio as an active methodology and assessment method depends on the participation and interest of students and teachers. Conclusion: Reflection in the teaching-learning process becomes possible with the use of active methodologies. As implications for nursing practice, the portfolio proved to be an efficient strategy for the expansion of theoretical knowledge, helping in the development of skills and competences of the profession.

Descritors: Nursing education; Learning; Educational evaluation.

\section{PERCEPCIONES DE ESTUDIANTES EN REFERENCIA SOBRE EL USO DE LA CARTERA REFLECTIVA}

Objetivo: analizar las percepciones de los estudiantes de pregrado de enfermería sobre el uso de la cartera reflexiva como método de enseñanza, aprendizaje y evaluación. Método: Investigación cualitativa, realizada en un grupo de estudiantes de Enfermeria, que desarrollaron portafolios para la disciplina Temas Especiales en Atención de Enfermería. Se utilizó un cuestionario sobre la percepción de los académicos en la construcción de la cartera con énfasis en los aspectos positivos y negativos del proceso. Los datos fueron categorizados por análisis de contenido temático. Resultados: Los resultados mostraron que el uso del portafolio es una herramienta para superar el modelo de enseñanza tradicional, con el objetivo de reflejar al alumno en el proceso de enseñanza-aprendizaje. El éxito del uso de la cartera como metodología activa y método de evaluación depende de la participación e interés de estudiantes y maestros. Conclusión: La reflexión en el proceso de enseñanza-aprendizaje se hace posible con el uso de metodologías activas. Como implicaciones para la práctica de enfermería, el portafolio demostró ser una estrategia eficiente para expandir el conocimiento teórico, ayudando a desarrollar las habilidades y competencias de la profesión.

Descriptores: Educación en enfermería; Aprendizaje; Evaluación educativa. 


\section{INTRODUÇÃO}

O processo de formação profissional do enfermeiro na contemporaneidade brasileira é resultado de diversas transformações ocorridas ao longo dos anos, atreladas ao modelo político-econômico-social vigente. O mundo globalizado tem conduzido esse processo sob novos modelos de construção do conhecimento que possibilitam a formação de profissionais competentes para o atendimento qualificado à saúde da populaçãol.

A integração entre o ensino superior, a sociedade e o mercado de trabalho constitui elemento essencial para o planejamento do processo de ensino-aprendizagem. A identificação de formas, métodos e conteúdos a serem desenvolvidos no processo formativo do profissional enfermeiro deve corresponder ao desenvolvimento social, econômico e cultural, segundo as necessidades em saúde dos sujeitos na perspectiva biopsicossocial ${ }^{2-3}$.

$\mathrm{Na}$ formação em Enfermagem, as práticas pedagógicas devem possuir como eixo norteador o aprender a cuidar do outro, tendo em vista a sua condição singular e integral de existência. Com isso, é reconhecido que o processo educativo e o processo de cuidar se dão no âmbito de relações interpessoais 4 .

Para o estabelecimento de um processo ensino-aprendizagem sólido e instigador no campo da Educação em Enfermagem, podemos inferir que o alcance de uma Aprendizagem Significativa é concebido a partir de elementos como compreensão, reflexão e atribuição de significados ao cuidado. Com isso, emprega-se a Aprendizagem Significativa na educação dos estudantes de Enfermagem tendo como objetivo a reelaboração de conceitos a partir do conhecimento prévio e da retenção do que faz sentido e tem significado no aprender a cuidar ${ }^{5}$. Emerge, nesse contexto, a necessidade de superação dos modelos tradicionais de ensino perpetuados na história, e sua substituição por novas estratégias pedagógicas que coloquem a pessoa e sua subjetividade no centro do processo ensino-aprendizagem. As metodologias ativas representam essas estratégias ao desdobrarem-se em tendências pedagógicas através das quais o estudante de Enfermagem se torna o protagonista central, corresponsável por sua trajetória educacionalt.

Nesse cenário, o portfólio se configura como sendo uma metodologia interessante para a avaliação e desenvolvimento das atividades voltadas para a prática profissional, a qual proporciona a reflexão e a articulação de saberes teóricos usados no processo de trabalho. Por meio dessa ferramenta, o estudante agrupa anotações, resumos, relatórios e reflexões, para que em seguida possa estabelecer o que é mais significativo segundo suas experiências, o que evidencia seu avanço ou sua persistência em dificuldades não solucionadas ${ }^{7}$.

Diante do exposto, objetiva-se analisar as percepções de estudantes de graduação em Enfermagem sobre a utilização do portfólio como método de ensino, aprendizagem e avaliação.

\section{MÉTODO}

\section{Tipo de estudo}

Estudo qualitativo realizado com estudantes de Enfermagem.

Local de estudo

Curso de Enfermagem do interior do Estado do Ceará.

\section{Participantes do estudo}

Participaram da pesquisa estudantes da disciplina Tópicos Especiais do Cuidado de Enfermagem, ofertada no 8o semestre do Curso de Enfermagem. Apesar da não exigência de pré-requisitos para cursá-la, todos os participantes estavam na fase pré-estágio do curso.

Participaram do estudo 19 acadêmicos regularmente matriculados na disciplina Tópicos Especiais do Cuidado de Enfermagem. Como critério de inclusão utilizou-se estar cursando a disciplina Tópicos Especiais do Cuidado de Enfermagem e como critério de exclusão estudantes que tenham se evadido durante o semestre.

\section{Coleta de dados}

Os dados foram coletados durante o período de agosto a dezembro de 2016. Os estudantes desenvolveram portfólios como parte complementar do processo de ensino-aprendizagem da disciplina Tópicos Especiais do Cuidado de Enfermagem. Primeiramente, os estudantes foram norteados no que se refere ao método a ser usado para a preparação do portfólio durante o semestre, no qual foram destacados os objetivos do emprego de tal metodologia: método de aprendizagem e avaliação educacional que leva o acadêmico à reflexão, à autonomia, à liberdade de expressão e à criatividade. As temáticas abordadas durante as aulas foram definidas por prioridade da turma, elencando temas relacionados ao cuidado de Enfermagem, práticas e contextos assistenciais. Sendo assim, os marcos formativos durante a disciplina correspondem às demandas apresentadas pelos estudantes no início do semestre, correspondendo às necessidades de aprendizagem consideradas prioritárias para o ingresso nos campos de prática.

Após cada aula, os estudantes deveriam repassar para o portfólio o que aprenderam e o que mais significou no aprendizado. O portfólio era apresentado na sala de aula duas vezes durante o semestre, correspondendo a duas notas de avaliação do semestre. O professor avaliava o conteúdo de maneira formativa, conforme os objetivos propostos durante o semestre, fornecendo assim um feedback. A avaliação educacional não era realizada somente pelo professor, mas 
também de forma individual e em conjunto com os colegas de sala, resultando a nota final. Ademais, o professor realizava uma avaliação do desempenho e evolução durante a construção do portfólio de cada estudante, sendo questionadas as dificuldades, limitações, desempenho e crescimento em relação à aprendizagem de cada estudante.

Ao final do semestre, foi realizada a aplicação de um questionário com os estudantes, cujo propósito era conseguir dados sobre a percepção dos acadêmicos a respeito da importância do portfólio como metodologia ativa de ensino-aprendizagem e como método de avaliação educacional para identificar os pontos positivos e negativos sobre seu uso. $\mathrm{O}$ questionário utilizado foi composto por cinco perguntas: "Como você se sente em relação ao aprendizado sobre cuidado de Enfermagem?"; "Fale um pouco sobre sua experiência durante esse semestre. O que foi significativo para sua aprendizagem?"; "Quais as dificuldades e/ou limitações no processo de educação em Enfermagem?"; "A construção do portfólio acadêmico foi algo proveitoso para o seu aprendizado?"; "Considerando a forma como a disciplina foi desenvolvida, o que é importante manter, abandonar e/ou ampliar para a melhoria do aprendizado?".

\section{Procedimentos de análise e tratamento dos dados}

Após a transcrição integral das falas, as informações da pesquisa foram examinadas sob os pressupostos da análise de conteúdo do tipo categorial temática ${ }^{7}$, cumprindo-se suas três fases essenciais: pré-análise, exploração do material, tratamento dos resultados e interpretação. Assim, o processo analítico adotado evidenciou as seguintes categorias temáticas: "Caminhos do processo formativo para o cuidado de Enfermagem: de uma visão limitante da saúde à necessária atualização na prática assistencial"; e, "Portfolio como instrumento reflexivo e significativo na formação em Enfermagem: reconstrução de saberes e desenvolvimento profissional".

\section{Aspectos éticos}

A presente pesquisa obedeceu aos aspectos éticos e legais que estão dispostos na Resolução № 466/12 e Resolução № 510/16 do Conselho Nacional de Saúde (CNS) ${ }^{9-10}$, sendo aprovada pelo Comitê de Ética em Pesquisa, sob o Parecer № 974.796.

\section{RESULTADOS}

- Caminhos do processo formativo para o cuidado de Enfermagem: de uma visão limitante da saúde à necessária atualização na prática assistencial

Ao serem questionados como se sentiam em relação ao aprendizado sobre os cuidados de Enfermagem, emergiram narrativas direcionadas, sobretudo, para uma visão ampliada de saúde, na qual devemos observar a prática cuidadora no processo saúde-doença, em sua diversidade de fatores biopsicossociais

[...] um olhar mais ampliado, enxergando além da doença e vendo o paciente como um todo (E8).

[...] envolve inúmeros fatores biopsicossociais e várias definições sobre o cuidado, e nenhuma está errada ou correta completamente, uma completa a outra [...] (E7).

Emerge no processo de ensino-aprendizagem que o cuidado de Enfermagem deve ser uma assistência que ocorra de modo holístico e integral, no qual o paciente deva ser compreendido em seu contexto específico, além de ser realizado de maneira humanizada e reflexiva, como narram a seguir:

$O$ cuidado de Enfermagem deve ser integral, holístico e subjetivo, compreender o indivíduo dentro do seu contexto [...] (El8).

O cuidado foi empoderado, humanizada e reflexivo (Ell).

Sobre o cuidado de Enfermagem, os participantes expõem que sempre existirá a necessidade de formação e atualização, pois a prática de Enfermagem é diferenciada e minuciosa, exigindo atenção no trabalho cotidiano.

[...] sempre haverá melhorias para se realizar; [...] o cuidar de um modo geral é algo especial, minucioso e ao qual devemos voltar toda nossa atenção já que consiste na nossa ferramenta de trabalho (E5).

No que se refere às dificuldades e/ou limitações no processo de formação em Enfermagem, as respostas apresentam, de maneira recorrente, críticas quanto à escassez de recursos e infraestrutura na universidade pública.

As condições estruturais, ou falta de materiais para práticas de algumas disciplinas na universidade (El2)

[...] estrutura física deficiente, que acaba atrapalhando o processo de formação (ElO).

Detalhadamente, as atividades práticas do processo formativo são vivenciadas em quantidade insuficientes, bem como a ausência de oportunidades para a realização dos procedimentos práticos de assistência à saúde adquiridos durante as aulas teóricas, motivos pelos quais os estudantes ficam, 
diversas vezes, "presos" somente à parte teórica. Observa-se uma discrepância entre atitudes práticas e atividades teóricas na formação.

A questão dos estágios que são insuficientes para a aplicação dos nossos conhecimentos em práticas de assistência em saúde (Ell).

Dinamismo e oportunidades de realizar os procedimentos nos momentos dos estágios [...] (E3).

Ficar "preso" apenas na questão teórica [...] (E15).

A partir das discussões em sala de aula sobre o cuidado de Enfermagem, um fato considerado relevante, por parte dos estudantes, é a desvalorização da categoria profissional e desarticulação para garantir direitos. Vejamos:

[...] falta de valorização da profissão (El).

[...] uma classe desunida, que luta pelos direitos que não são seus e esquece-se de lutar por seu espaço (E7).

- Portfolio como instrumento reflexivo e significativo na formação em Enfermagem: reconstrução de saberes e desenvolvimento profissional

A elaboração do portfólio se mostrou uma técnica de ensino-aprendizagem bastante significativa por parte dos estudantes, pelo fato de proporcionar um reforço do conhecimento já adquirido, além da reconstrução de novos saberes.

A construção do portfólio foi muito significativa, já que reforçava o que a gente já sabia e construía novos conhecimentos (E4).

Aprender sobre a estrutura e significado do próprio portfolio (El4).

A aplicação de práticas e modos de ensino-aprendizagem, com ênfase nas metodologias ativas, proporcionou a realização de reflexões sobre a aprendizagem e seus significados na percepção dos estudantes, conforme demonstram as falas a seguir:

[...] utilizar metodologias ativas que era uma coisa na qual tínhamos dificuldade e não gostáuamos (El2).

[...] principais pilares da aprendizagem significativa (E6).
[...] observar as inúmeras formas de abordar um tema, não somente aquele modelo tradicional [...] (E7).

[...] conteúdos bem complexos de maneiras bem interessante (E8)

[...] perceber que a aprendizagem pode se dar de muitas formas [...] (E9).

Além dos benefícios formativos apontados nas falas anteriores, a utilização de metodologias ativas na realização de trabalhos em equipe proporciona maior contato e aproximação com os demais colegas, o que facilita o cotidiano acadêmico. As relações interpessoais fazem parte do cotidiano profissional, dessa forma, o estímulo dessa habilidade durante a graduação facilitará um bom desenvolvimento de suas atividades futuras dentro do campo profissional.

[...] o quanto é importante o trabalho em equipe (E3).

As atividades em grupo foram de grande valia, na percepção de envolvimento com pessoas que não tínhamos tanto contato (E19).

Quando indagados sobre a construção do portfólio como um instrumento relevante para o seu aprendizado, notou-se que ele se apresenta como uma metodologia de ensino que favorece a fixação de saberes, incentivando a participação dos alunos a realizarem pesquisas sobre as temáticas abordadas, o que demonstra um auxilio para o desenvolvimento de reflexões críticas.

[...] é uma metodologia que vem nos ajudar a fixar os conhecimentos, tantos os prévios como os aplicados (ElO).

[...] incentiva um envolvimento mais com os temas, a buscar, realmente aprender (E6).

[...] me fez pesquisas sobre os temas e fazer uma reflexão crítica a respeito de cada um. Além de me empenhar na produção do mesmo e na elaboração da aula de minha responsabilidade (El4).

Para a maioria dos entrevistados, o portfólio funciona como base de dados para futuras consultas, pois está repleto de saberes, e funcionará como um banco de dados para suprir possiveis dúvidas na prática profissional. 
[...] em caso de futuras dúvidas, tenho onde consultar (E6).

[...] vai ser minha fonte de consulta, pois guardei muitas informações valiosas nele (E8).

Contudo, para alguns participantes, a construção do portfólio limita-se a uma técnica momentânea de aprendizado, sendo frágil para utilização futura. Nesse caso, foi referida a preferência pela utilização de métodos tradicionais, conforme demonstra a fala abaixo:

[...] não achei muito proveitoso. É um material que eu não usaria para consulta. Prefiro os métodos tradicionais (El).

Na perspectiva relacional, as narrativas abaixo evidenciam questões referentes à manutenção do dinamismo proposto, bem como enfatizam o uso dessas metodologias ativas como estratégia para desencadear uma interação mais próxima entre estudantes e professor. Em destaque para o processo de acolhimento em sala de aula, discussões temáticas, leituras de artigos, de modo a identificar potencialidades e fragilidades no ensino de Enfermagem.

Manter as dinâmicas e a subjetividade nos conteúdos (El).

Manter o dinamismo, acolhimento e interdisciplinarmente, como também o valor atribuído ao conhecimento trazido pelos alunos (E5).

É muito importante manter a metodologia, pois aproxima e iguala o professor ao aluno, ajudando na troca e agregação de conhecimento, enfatizando o ser humano como um ser pensante e afetivo (Ell).

Deve manter a identificação das potencialidades e fragilidades e também a forma de ensino (E12)

Ademais, os participantes foram questionados em relação a possiveis melhorias e ampliações para o emprego dessas metodologias na disciplina em questão. Pode-se observar nas falas seguintes algumas sugestões apontadas, a saber: melhor interação dos docentes retratando experiências, bem como da turma; consistência no aporte teórico que deve ser trazido pelas equipes de estudantes e uma explanação mais detalhada sobre a produção do portfólio.

Ampliar o afeto durante as aulas, a união da turma, a subjetividade (El).
Nas temáticas operativas os docentes podiam participar consolidando o que foi retratada pelos alunos (E3).

Sugiro orientar as equipes a utilizar um aporte teórico maior e não apenas trazer dinâmica sem a turma saber/conhecer o conteúdo (E9).

Deveria melhorar, a participação do professor durante as atividades, colaborando com suas experiências vividas (E19).

Um ponto negativo exposto nas entrevistas indica que a construção do portfólio se mostra como algo que deve ser bem elaborado e planejado, o que para muitos pode tornar-se um trabalho difícil e exaustivo.

Abandonar o rigor com a produção do portfólio (El).

Desse modo, para o aumento da criatividade e ampliação das possibilidades de registro, a rigidez que envolve o processo de confecção do portfólio está expressa como algo a ser flexibilizado.

\section{DISCUSSÃO}

A formação para o cuidado de Enfermagem deve possuir uma abordagem mais ampla, além do processo saúde-doença, de modo que possibilite um novo entendimento da complexidade do ser humano numa perspectiva biopsicossocial, proporcionando uma visão ampliada de saúde $\mathrm{e}^{11-12}$.

Os achados desta investigação sobre os elementos que constituem o cuidado de Enfermagem são semelhantes a estudos de naturezas semelhantes ${ }^{13-14}$, os quais identificaram a humanização, holismo e a integralidade na assistência como sendo essenciais para o oferecimento de um cuidado de qualidade. Ressalta-se que é essencial destacar que o cuidado que acontece como sendo uma atividade mecânica perde parte de sua essência ${ }^{15}$, para tanto, é preciso que o ser humano seja tomado holisticamente, um ser único e integral.

Os resultados enfatizam a necessidade de permanente atualização sobre as inovações da prática, as quais têm como propósito trazer benefícios para com o cuidado ao paciente $\mathrm{e}^{16}$. Essas inovações favorecem o aperfeiçoamento das técnicas de trabalho na assistência ao paciente, para um cuidado prestado com eficiência e resolubilidade.

Em relação às experiências consideradas significativas, as práticas grupais são concebidas como um conjunto de pessoas reunidas com a finalidade de criar sinergia, as quais 
estão relacionadas com a comunicação, proporcionando a criação de vínculo entre os membros do grupo. Desse modo, temos melhores resultados do que aqueles obtidos por meio da mera junção de resultados individuais ${ }^{17-18}$.

A utilização das metodologias ativas pode proporcionar a autonomia do estudante, despertando a sua curiosidade e estimulando a tomada de decisões, mostrando as diversas maneiras de abordar temas que, muitas vezes, são considerados complicados com a aplicação tradicional de ensino ${ }^{19}$. As metodologias ativas potencializam o processo ensino-aprendizagem para que estudantes e professores fomentem a formação crítica para as diversas áreas.

A construção do portfólio se torna um instrumento-estratégico de estimulação do pensamento reflexivo, pelo fato de o mesmo proporcionar ao educando as ações de documentar, registrar e estruturar os processos de sua própria aprendizagem ${ }^{20}$, sendo que a sua elaboração é estabelecida entre o docente e o discente na realização de um trabalho de colaboração e na resolução de problemas complexos e situacionais. Esse método de ensino visa a identificação e maximização do potencial de cada estudante na sistematização de seus interesses, estilos de aprendizagem e de expressão condizentes com sua subjetividade e significação ${ }^{21}$.

A pesquisa mostrou que, dentre as dificuldades para o ensino de Enfermagem, a infraestrutura física da instituição é apontada como sendo um fator que pode ser desfavorável, como a falta de bibliotecas com acervo atualizado e de laboratórios especializados para o ensino e a pesquisa, salas de aulas com equipamentos inadequados e sistema de ventilação precário ${ }^{22}$.

Ainda se observa que a articulação entre a teoria e a prática ainda não é evidenciada como deveria, sendo explorada de forma superficial ao longo do processo de formação do enfermeiro. Esse distanciamento entre teórico-prática pode ser percebido quando o profissional recém-formado se depara com situações que the parecem absolutamente novas, visto que não foram vivenciadas durante sua formação ou o foram de modo distinto da realidade profissional ${ }^{23}$.

Outro fator abordado é a incapacidade do profissional de Enfermagem em valorizar sua profissão, o que ameaça a sua própria visibilidade ${ }^{24}$. Nesse ínterim, torna-se necessário que a Enfermagem assuma um posicionamento mais proativo neste cenário.

Ressalta-se ainda que a ausência de um bom relacionamento, a comunicação deficiente em conjunto com o não desenvolvimento de trabalho em equipe e a falta de cooperação interferem de modo direto no seguimento natural das atividades, resultando em descontentamento e desconforto para quem cuida e quem é cuidado ${ }^{25}$. Dessa forma, fica evidente a necessidade de união e cooperação por parte dos profissionais, com a finalidade de se obter melhorias para a categoria.

A aplicação do portfólio como método de aprendizagem vem sendo utilizada há décadas, e mostra-se como uma ferramenta útil, sobretudo para a autonomia do estudante em um mundo globalizado e mais apto às tecnologias voltadas para resolução de atividades cotidianas, como o aprendiza$\mathrm{do}^{26}$. Embora as metodologias ativas tenham notoriedade entre os estudantes ao longo do tempo, alguns ainda preferem o ensino que é realizado de modo tradicional, no qual o professor é o único mediador do conhecimento e principal responsável por conduzir o processo educativo ${ }^{6,27}$.

O portfólio é um instrumento capaz de estimular o pensamento crítico e reflexivo, visto que por meio dele o estudante poderá comprovar, organizar e manter um processo para sua aprendizagem atual e futura, reunindo, além dos conteúdos, suas dúvidas, anseios, questionamentos, opiniões, sentimentos, também suas vivências interpessoais ${ }^{20}$

As propostas realizadas por meio das metodologias ativas fazem com que o estudante seja o centro de todo o processo, dando-lhe reponsabilidades e autonomia na sua jornada acadêmica e construção do conhecimento sem tirar a atuação do professor que é de fundamental importância no sentido de proporcionar experiências aos estudantes capazes de alcançar os objetivos estabelecidos ${ }^{28}$.

Além disso, o ato de aprender é um processo de construção e reconstrução que permite estabelecer diferentes modos de relações entre fatos e objetos, fazendo com que uma cadeia de ressignificações seja descoberta, podendo ser utilizada nas mais diversas situações ${ }^{28}$.

Partindo do pressuposto que o indivíduo é o ser que constrói sua própria história, sendo ele o protagonista dela, percebe-se a importância do ensinar de modo a considerar cada sujeito, exigindo o respeito, a autonomia e dignidade deste. Deve existir uma relação de companheirismo entre o docente e o discente, de modo que cada um dependa do outro no processo de ensino-aprendizagem e na troca de saberes ${ }^{29}$.

Por fim, o docente, responsável por conduzir todo o processo necessita apreender e desenvolver novas habilidades e dinamismo, permitindo que o discente tenha vontade de participar ativamente do processo de ensino ${ }^{29}$.

\section{LIMITAÇÕES DO ESTUDO}

A escassez de estudos envolvendo a temática do uso de portfólios no Ensino de Enfermagem contribuiu negativamente para a ampliação da discussão e argumentação dos resultados encontrados, além do pequeno quantitativo de participantes do estudo, tendo em vista os outros semestres e disciplinas. 


\section{Contribuições para A Prática}

Esse estudo contribui para reflexões referentes ao Ensino de Enfermagem e o processo ensino-aprendizagem envolvido, englobando novas tecnologias e modelos de avaliações formativas. Direciona estudantes e formadores a repensarem sempre o modelo pedagógico proposto de modo a adequá-lo à necessidade e realidade dos envolvidos.

\section{CONCLUSÃO}

As percepções de estudantes de Enfermagem sobre a utilização do portfólio são conformadas em um contexto no qual as potencialidades e fragilidades se apresentam concomitantemente. Nesse processo formativo, elucidou-se uma relação proficua entre a produção do portfólio e o estímulo da criticidade com vistas ao cuidado de Enfermagem. Genericamente, os acadêmicos reconhecem o portfólio como instrumento reflexivo e significativo para a reconstrução de saberes e desenvolvimento profissional.

Assim, foi possivel constatar que os trabalhos realizados em equipe na elaboração do portfólio tiveram impacto positivo entre os estudantes, proporcionando maior vínculo entre estes e a ampliação de seus conhecimentos. Enfatizam-se ainda, nas percepções dos entrevistados, limitações relacionadas à falta de estrutura da instituição de ensino e à insuficiente articulação entre teoria e prática, o que pode implicar diretamente no processo formativo.

Destarte, o uso do portfólio como uma metodologia ativa e método de avaliação educacional está relacionado à participação ativa e ao interesse dos estudantes e professores. Pode-se inferir que a sua aplicabilidade no processo ensino-aprendizagem traz implicações para a prática de Enfermagem. No contexto investigado, o portfólio mostrou-se uma estratégia eficiente para a ampliação do conhecimento teórico, auxiliando no desenvolvimento das habilidades e competências essenciais para a formação em Enfermagem.

Contribuições dos Autores: Todos os autores contribuíram em todas as etapas do manuscrito.

\section{REFERÊNCIAS}

1. Silva MG, Fernandes JD. Teixeira GAS, Silva RMO. Contemporary formal nursing education process: challenges and perspectives. Texto Contexto Enferm [Internet]. 2010 Jan/Mar [cited 2017 May 21]; 19(1):176-84. Available from: http://www.scielo.br/pdf/tce/v19n1/v19nla21.pdf. http://dx.doi.org/10.1590/s0104-07072010000100021.

2. Ortega MCB, Cecagno D, Lior AMS, Siqueira HCH, Montesinos MJL, Soler LM. Academic training of nursing professionals and its relevance to the workplace. Rev. Latino-Am. Enfermagem [Internet]. 2015 May/June [cited 2017 May 21]; 23(3):404-10. Available from: www.scielo.br/pdf/rlae/v23n3/pt_0104-1169-rlae-23-03-00404.pdf. https://doi. org/10.1590/0104-1169.0432.2569.

3. Ximenes Neto FRG. Educação em Enfermagem no Brasil: avanços e riscos. Enferm. Foco [Internet]. 2019 [cited 2020 July 13]; 10(6):4-5. Available from: http://revista.cofen. gov.br/index.php/enfermagem/article/view/3368/643 https://doi.org/10.21675/2357-707X.2019.v10.n6.3368.

4. Castro M, Pereira WR. Integral care: conceptions and practices of Nursing professors. Rev Bras Enferm [Internet]. 2011 May/June [cited 2017 May 21]; 64(3):486-93 Available from: www.scielo.br/pdf/reben/v64n3/v64n3al2.pdf. http://dx.doi.org/10.1590/\$0034-71672011000300012.

5. Sousa ATO, Formiga NS, Oliveira SHS, Costa MML, Soares MJGO. Using the theory of meaningful learning in nursing education. Rev Bras Enferm [Internet]. 2015 July/Aug [cited 2017 May 21]; 68(4):713-22. Available from: http://www.scielo.br/pdf/reben/v68n4/en_0034-7167-reben-68-04-0713.pdf. http://dx.doi.org/10.1590/0034-7167.2015680420i.

6. Prado ML, Velho MB, Espindola DS, Sobrinho SH, Backes VMS. Charles Maguerez Arc: reflecting methodology strategies on active training for health professionals. Esc Anna Nery [Internet]. 2012 Mar [cited 2017 May 02]; 16(1):172-7. Available from: http://www.scielo.br/scielo.php?script=sci_arttext\&pid=S1414-81452012000100023. http://dx.doi. org/10.1590/S1414-81452012000100023

7. Rigo MPM, Ghisleni MM, Ely LS, Freitas EM,Sehnem E, Adami FS. Portfólio como instrumento de aprendizagem e avaliação. Revista Eletrônica Debates em Educação Cientifica e Tecnológica [Internet]. 2016 June [cited 2017 May 24]; 6(2):46-57. Available from: http://ojs.ifes.edu.br/index.php/dect/article/view/289/382.

8. Minayo MCS. O desafio do conhecimento. Pesquisa Qualitativa em Saúde. 12a ed. São Paulo: Hucitec; 2010.

9. Ministério da Saúde (BR). Conselho Nacional de Saúde. Comissão Nacional de Ética em Pesquisa. Resolução no 466, de 12 de dezembro de 2012. Dispõe sobre as diretrizes e normas regulamentadoras de pesquisas envolvendo seres humanos. Diário Oficial da República Federativa do Brasil, Brasília (DF), 2013 jun 13: Seção 1:59. [Internet]. 2012 [cited 2017 May 24]. Available from: https://bvsms.saude.gov.br/bvs/saudelegis/cns/2013/res0466_12_12_2012.html.

10. Ministério da Saúde (BR). Conselho Nacional de Saúde. Comissão Nacional de Ética em Pesquisa. Resolução no 510 , de 07 de abril de 2016 . Dispõe sobre as normas aplicáveis a pesquisas em Ciências Humanas e Sociais cujos procedimentos metodológicos envolvam a utilização de dados diretamente obtidos com os participantes ou de informações identificáveis ou que possam acarretar riscos maiores do que os existentes na vida cotidiana. Diário Oficial da República Federativa do Brasil, Brasilia (DF), 2016 may 24; Ed. 98. Seção 1:44. [Internet]. 2012 [cited 2020 July 13]. Available from: http://www.in.gov.br/materia/-/asset_publisher/KujrwOTZC2Mb/content/id/22917581.

11. Rangel RF, Costenaro RGS, Itha S, Zamberlan C, Siqueira HCH. Backes DS. Formação para o cuidado integral: percepção de docentes e discentes de Enfermagem. Revista de Pesquisa: Cuidado é Fundamental Online [Internet]. 2017 Apr 11; [cited 2019 Sep 6]: 9(2):488-494. Available from: http://www.seer.unirio.br/index.php/cuidadofundamental/ 
article/view/5450

12. Brito MCC. Araújo RMBV. Dias MSA, Silva LCC. Rodrigues PV. Moita MP. Análise da ocorrência de estresse entre estudantes de enfermagem. Enferm Foco [Internet]. 2019 [cited 2020 July 13];10(6)70-78. Available from: http://revista.cofen.gov.br/index.php/enfermagem/article/view/2391/653. https://doi.org/10.21675/2357-707X.2019. v10.n6.2391.

13. Medeiros SP, Oliveira ACC, Piexak DR, Silva LL, Oliveira AMN, Fornari NC. Percepción de universitarios sobre la recepción de toque terapéutico. Revista De Pesquisa: Cuidado é Fundamental [Internet] 2019 [cited 2019 Jun 9]; 11(2):464-9. Available from: http://ciberindex.com/c/ps/P112028. http://dx.doi.org/10.9789/2175-5361.2019. vlli2.464-469.

14. Oliveira JLC, Papa MAF, Wisniewski D, Inoue KC. Costa MAR, Matsuda LM et al. Quality of care: concepts from nursing students. Rev Min Enferm [Intternet]. 2015 Jan/ Mar [cited 2017 May 04]; 19(1):29-35. Available from: http://www.reme.org.br/artigo/detalhes/983. http://dx.doi.org/10.5935/1415-2762.20150003.

15. Carvalho DO, Santos NNRC, Silva ARV, Carvalho GCN. Percepção do profissional de enfermagem acerca do cuidado humanizado no ambiente hospitalar. Revista interdisciplinar [Internet]. 2015 jun/set [citado em 2019 Set. 7]; 8(3):61-74. Available from: https://revistainterdisciplinar.uninovafapi.edu.br/index.php/revinter/article/ view/680/pdf_237.

16. Lowen IMV. Peres AM, Ros C, Poli Neto P. Faoro NT. Innovation in nursing health care practice: expansion of access in primary health care. Rev Bras Enferm [Internet]. 2017:70(5):898-903. Available from: http://dx.doi.org/10.1590/0034-7167-2016-0131.

17. Silva KL, Barcelos BJ, França BD, Araújo FL, Magalhães Neta IT, Ledo MM. Between experiments and experiences: challenges for teaching competencies for health promotion in Nursing Education. Interface (Botucatu) [Internet]. 2018 [cited 2018 Nov 12]; 22(67):1209-20. Available from: http://www.scielo.br/pdf/icse/v22n67/1807-5762-icse-1807-576220170467.pdf. http://dx.doi.org/10.1590/1807-57622017.0467

18. Baia RSM, Vasconcelos EV, Silva SED. Freitas KO, Gonçalves LHT. Moodle no processo educacional de enfermagem: avaliação na perspectiva do alunado. Enferm em Foco [Internet]. 2017 [cited 2020 Mar 26]; 8(2):31-35. DOI https://doi.org/10.21675/2357-707X.2017.v8.n2. Available from: http://revista.cofen.gov.br/index.php/enfermagem/issue/view/25.

19. Mourthé Junior CA, Lima VV, Padilha RQ. Integrating emotions and rationalities for the development of competence in active learning methodologies. Interface (Botucatu) [Internet]. 2018 [cited 2018 Nov 12]; 22(65):577-88. Available from: http://www.scielo.br/pdf/icse/v22n65/1807-5762-icse-1807-576220160846.pdf. http://dx.doi. org/10.1590/1807-57622016.0846

20. Cotta RMM, Costa GD. Assessment instruments and self-evaluation of reflective portfolios: a theoretical-conceptual construction. Interface, comunicação, saúde e educação (Botucatu) [Internet]. 2016 Mar [cited 2019 Sep 07]; 20(56):171-183. Available from: http://www.scielo.br/scielo.php?script=sci_arttextசpid=S1414-328320160001001718lng=en. http://dx.doi.org/10.1590/1807-57622014.1303.

21. Schmitt CS, Domingues MJCS. Estilos de aprendizagem: um estudo comparativo. Avaliação (Campinas) [Internet]. 2016 [cited 2018 Nov 12]: 21(2):361-86. Available from: http://www.scielo.br/pdf/aval/v2ln2/1982-5765-aval-21-02-00361.pdf. http://dx.doi.org/10.1590/S1414-40772016000200004.

22. Davok DF. Bernard RP. Evaluation of attrition rates in undergraduate programs at THE State University of Santa Catarina - UDESC. Avaliação, Campinas. [Internet] 2016 July [cited 2017 Apr 29]; 1(2):503-21. Available from: www.scielo.br/pdf/aval/v21n2/1982-5765-aval-21-02-00503.pdf. http://dx.doi.org/10.1590/S141440772016000200010 .

23. Trevisan DD, Minzon DT, Testi CV, Ramos NA, Carmona EV, Silva EM. Education of nurses: detachment between undergraduation courses and professional practices. Cienc Cuid Saude. 2015 Apr/June [cited 2017 Apr 29]; 12(2):331-37. Available from: www.periodicos.uem.br/ojs/index.php/CiencCuidSaude/article/viewFile/19643/pdf. http://dx.doi.org/10.4025/cienccuidsaude.v12i2.19643.

24. Lage CEB, Alves MS. (Des)valorização da Enfermagem: implicaçōes no cotidiano do Enfermeiro. Enfermagem em foco [Internet]. 2016 [cited 2019 Set. 7]; 7(3/4):12-16. Available from: http://revista.cofen.gov.br/index.php/enfermagem/article/view/908.

25. Wisniewski D, Silva ES, Évora YDM, Matsuda LM. The professional satisfaction of the nursing team vs. Work conditions and relations: a relational study. Texto contexto - enferm. [Internet]. 2015 Sep [cited 2019 Sep 07]; 24(3):850-858. Available from: http://www.scielo.br/scielo.php?script=sci_arttext\&pid=S0104-07072015000300850\&lng=en. http://dx.doi.org/10.1590/0104-070720150000110014.

26. Rempel C, Grave MTQ. Fassina P. Johann L. Bitello AR. Experiences of Professors Taking Part of the Project Qualifica/Univates/ Lajeado/RS with Active Learning Methods. Revista Tempos e Espaços em Educação. [Internet] 2016 May/Aug [cited 2017 May 02]; 9(19):39-50. Available from: https://seer.ufs.br/index.php/revtee/article/ view/5594/0. http://dx.doi.org/10.20952/revtee.v9i19.5594.

27. Marin MJS, Lima EFG, Paviotti AB, Matsuyama DT, Silva LKD, Gonzalez C, Druzian S, Ilias M. Strengths and weaknesses in the use of active learning methods. Rev. bras. educ. med. [Internet] 2010 Jan/Mar [cited 2017 May 02]; 34(1):13-20. Available from: http://www.scielo.br/pdf/rbem/v34nl/a03v34nl. http://dx.doi.org/10.1590/S010055022010000100003.

28. Gomes MPC, Ribeiro VMB, Monteiro DM, Leher EMT, Louzada RCR. The use of active learning methodologies in graduate courses in health and social sciences - students's evaluation. Ciênc. educ. [Internet] 2010 [cited 2017 May 02]; 16(1):181-198. Available from: http://www.scielo.br/pdf/ciedu/vl6nl/vl6nlall. http://dx.doi.org/10.1590/ S1516-73132010000100011.

29. Farias PAM, Martin ALAR, Cristo CS. Aprendizagem ativa na educação em saúde: percurso histórico e aplicações. Revista brasileira de educação médica [Internet]. 2015 jan/mar [cited 2019 Set. 7]; 39(1):143-158. Available from: http://www.scielo.br/scielo.php?pid=S0100-550220150001001438script=sci_arttext\&tlng=es. 